\title{
VERBAL MEANS OF EXPRESSING KIN RELATIONS IN THE LEXICON OF DIALECT SPEAKERS (BASED ON THE SPEECH OF RESIDENTS FROM MULTI-ETHNIC AREAS OF THE VOLGOGRAD REGION)
}

\author{
Natalya A. Starodubtseva \\ Volgograd State University, Volgograd, Russian Federation
}

\begin{abstract}
In this article, the part of the lexicon of a dialect speaker limited by verbs characterizing different types of kinship and in-law relations is described on the basis of the field approach. The study of the linguistic means has shown that the identified lexical units have typical semantics 'making family relations as a result of some ceremonies, circumstances and conditions', 'the type of interrelationship between relatives', 'the breakdown / loss of kin relations' that can have particular meanings. Based on the speech of the residents of the multi-ethnic areas of the Volgograd Region (Don Cossacks and Ukrainians - aborigines, migrants and their descendants), the usual and occasional linguistic means forming the core and periphery zone of the semantic field "Family relationships" are identified. The differences of the lexical units that constitute the core zone, the circumnuclear zone, the close periphery, and the far periphery are shown. The analysis of verbs was conducted according to four criteria (paradigmatic, syntagmatic, epidigmatic, and functional) and contributed to the identification of the componental structure of each segment of the field.

The lexical parallels (equivalents and analogues) used to express the analysed semantics have been identified in the lexicon of a dialect speaker. It has been found out that the verbs of interrelationship and interpersonal relations form the circumnuclear zone. The close periphery includes the verbs of speech, entity, emotional state, social relations; the far periphery includes the verbs of movement, physical impact on an object, social activity, functional state that are used as irregular means expressing the semantics of family relationships in the structure of the analysed lexicon.
\end{abstract}

Key words: dialectology, oral speech, lexicon, verb, functional and semantic field, core, periphery.

УДК 81 '28

ББК 81.025 .7

Дата поступления статьи: 20.10.2016

Дата принятия статьи: 21.11.2016

\section{ГЛАГОЛЬНЫЕ СРЕДСТВА ВЫРАЖЕНИЯ РОДСТВЕННЫХ ОТНОШЕНИЙ \\ В ЛЕКСИКОНЕ ДИАЛЕКТОНОСИТЕЛЕЙ (НА МАТЕРИАЛЕ РЕЧИ ЖИТЕЛЕЙ ПОЛИЭТНИЧЕСКИХ ТЕРРИТОРИЙ ВОЛГОГРАДСКОЙ ОБЛАСТИ)}

\author{
Наталья Анатольевна Стародубцева \\ Волгоградский государственный университет, г. Волгоград, Российская Федерация
}


ниц, отнесенных к ядру, приядерной зоне, ближней и дальней периферии. Анализ семантики глаголов проводился по четырем критериям (парадигматическому, синтагматическому, эпидигматическому и функциональному) и позволил определить компонентный состав каждого сегмента поля.

В лексиконе диалектоносителей выявлены лексические параллели - полные / неполные эквиваленты и аналоги, используемые для выражения анализируемой семантики в речи диалектоносителей. Обнаружено, что к ядру и приядерной зоне относятся глаголы взаимоотношения и межличностных отношений. Ближняя периферия включает глаголы речевой деятельности, бытия, эмоционального состояния, социальных отношений, зону дальней периферии образуют единицы семантических групп движения, физического воздействия на объект, социальной деятельности, функционального состояния, выступающие неспециализированными и нерегулярными средствами выражения семантики 'родственные отношения' в структуре анализируемого лексикона.

Ключевые слова: диалектология, устная речь, лексикон, глагол, функционально-семантическое поле, ядро, периферия.

1

«Устный язык слишком часто ускользает от исследователя», - замечал Ш. Балли, говоря о необычайной трудности и сложности рассмотрения живой речи, изучение которой в то же время «обновило и будет и впредь обновлять лингвистику» $[1$, с. 94]. Это подчеркивает актуальность обращения к особенностям функционирования обиходно-разговорной речи жителей конкретной местности, имеющей региональное своеобразие, обусловленное влиянием традиционного диалекта, объективных социально- и культурно-исторических условий, которые оказывают воздействие на формирование мировосприятия (ценностных ориентиров) личности.

Материалом для изучения послужили записи спонтанных бесед с сельскими жителями и прямого интервьюирования собеседников методом открытого вопросника, сделанные во время полевых диалектологических экспедиций с 2009 по 2015 г. в Иловлинском (с. Большая Ивановка, х. Озерки), Киквидзенском (ст-ца Преображенская, села Завязка, Мачеха, Семеновка, хутора Дубровский, Калачевский, Калиновский), Урюпинском (ст-ца Тепикинская, х. Дьяконовский) районов Волгоградской области. Данные территории отличаются полиэтничностью и квалифицируются как пункты смешанного проживания представителей близкородственных культур русских и украинцев (см. об этом: $[5 ; 6 ; 11]$ ), а в лингвистическом отношении характеризуются соединением различных языковых пластов (см. об этом: [2-4]).
Расшифрованные тексты показали, что центральной темой в них выступает человек и его связи с окружающим миром. Важными с исследовательской точки зрения являются описания родственных взаимоотношений (см., например: [7; 8]), поскольку представления о семье, браке формируют картину мира индивида, позволяют раскрыть особенности восприятия действительности и являются важным фактором в определении мировидения этноса или группы этносов.

Целесообразным представляется изучение лексикона диалектоносителей с позиций полевого подхода (подробнее об этом см.: [10]). Такой анализ позволил, наряду с именной лексикой (см.: [7]), выделить обширную группу глаголов (а также глагольно-именных сочетаний), используемых для характеристики брачных и родственных связей.

2

Глагольные лексемы обнаруживают многообразие и специфику реализации понятия «родственные отношения» и могут быть квалифицированы как ядерные и периферийные средства выражения названной семантики.

Представленные в анализируемом материале глаголы имеют типовую семантику 'установление родственных связей посредством каких-либо обрядов, в связи с какими-либо обстоятельствами или условиями', 'характер взаимоотношений кого-либо с кем-либо в рамках родственных связей', 'нарушение / утрата родственных связей' и отражают способы ведения хозяйства и организацию семейного быта, иерархию и особенности взаимоотноше- 
ний в семье. Регулярными и специализированными средствами репрезентации типовой семантики выступают прежде всего глаголы взаимоотношения и межличностных отношений, а также глаголы иных лексико-семантических групп (ЛСГ): контекстуальные значения этих глагольных единиц позволяют включить их в структуру семантического поля «Родственные отношения». При этом обнаруживается взаимопроникновение различных систем внутри одного языка, которое проявляется в наличии многообразных лексических параллелей (аналогов, вариантов, дублетов, эквивалентов) [7; 9].

Типовая семантика 'установление родственных связей посредством каких-либо обрядов, в связи с какими-либо обстоятельствами или условиями' может быть представлена частными значениями:

- 'начальный период установления родственных связей';

- 'вступление в родственную связь посредством заключения брака (в том числе совершения обряда венчания)';

- 'установление духовного родства посредством обряда крещения';

- 'приведение к родственному взаимодействию, вызванное какими-либо объективными обстоятельствами'.

Первое из указанных значений связано с моментом знакомства и периодом добрачных отношений будущих супругов, а также их родственников. В лексиконе диалектоносителей отмечены лексемы положительного эмоционально-оценочного отношения (по)нравиться, дружить, продружить. Нравиться используется в речи информантов в значении «относиться к кому-либо с симпатией, вызывая у кого-либо, обычно у лиц противоположного пола, интерес, влечение к себе» (ТСРГ, с. 595): Он пришол с армии, искал в июни нивесту, а я тока приехала са Страхава. Да, вот, и панравилася ему, а он-мне. Так с армии пришол чистинький, пацтрелинный, аккуратный, вот панравился - и свадьба

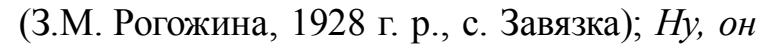
[будущий муж] гаварить: «А чё мне дяфчата, если ты мне нравишси!» (Е.С. Машлыкина, 1936 г. р., ст-ца Тепикинская).

Глагол дружить используется диалектоносителями как синоним лексемы встречаться в значении «поддерживать близкие от- ношения с кем-либо». Так, жительница с. Мачеха Т.И. Сахнова, 1942 г. р., отвечая на вопрос о том, как оказалась в здешних краях, замечает: Чо? Как папали? Чиво-чиво любоў! Падружылась, с Ванькай падружылась. Он атсюдава был; украинка А.Е. Сафронова из ст-цы Тепикинской, 1941 г. р., вспоминает особенности общения с будущим мужем: Я привыкла к этаму русскаму языку, пака мы с ним дружыли палтара года са сваим мужем. Он русский, а я украинка. С такой семантикой зафиксирован и глагол продружсть: Да, и вот три үо́ды мы с ним продружыли, фо симидисатавом замуш вышла, третива марта (А.П. Старухина, 1946 г. р., с. Мачеха). В качестве неполного эквивалента глагола встречаться жители указанных пунктов употребляют также просторечный глагол любиться, то есть «любить друг друга, находиться в любовных отношениях» (БАС, т. 6, с. 176): Так мы ж любилисьто на ферме, у нас тогда любовь какая была! [Какая?] Работали на ферме, там и все, и поженились и все, и ни дня не встречались (А.В. Александрова, 1936 г. р., х. Калиновский). Как видно из контекста, диалектоноситель разграничивает значения двух глагольных лексем - любиться и встречаться: последняя подразумевает свидания и встречи на досуге, в свободное время, чего молодежь тяжелого послевоенного времени была практически лишена.

В речи украинских жителей для обозначения начального этапа установления родственных связей используется глагол внешнего проявления отношения ухлёстывать, представленный в словарях со стилистической пометой «просторечное» и толкуемый как «ухаживать, волочиться за кем-либо» (БАС, т. 16, с. 1110): Ну и так вин [будущий муж] ухлыстыууал, ухльсстыуал, ухлыстыууал за мною. Я, конэшно, нэ дужэ хотила, но так пришлося (Е.А. Рыжих, 1929 г. р., с. Мачеха). Лексический повтор глагола ухлёстывать указывает в данном случае на интенсивность действия.

Синонимом рассмотренным языковым единицам можно считать глагол движения (c) ходить, выражающий последовательность действий лиц, устанавливающих родственное взаимодействие: Пришел я в пятьдесят чет- 
вертом уоду с армии... Она через хату... Раз сходил, други, третий, четвертый, пятый, десятый. Так и пошло (С. Бароменский, 1931 г. р., с. Мачеха).

К группе глаголов, характеризующих начальную стадию семейных, родственных отношений, могут быть отнесены и лексемы, используемые при описании традиций сватовства: глаголы ЛСГ контакта свататься, договариваться и др., а также контекстуально сближающиеся с ними глаголы речевой деятельности беседовать, говорить, разговаривать и др.: Ну как ани [свадьбы] раньшь прахадили?! Эта, паехали сваты, дагаварились, какое число свадьба, на какой день, вот и фсё (3.М. Рогожина, 1928 г. р., с. Завязка); Спирва я пошол сам пауаварил, ну патом радителей приүласил. Пришли, приехали. Ну, да этава мы, канешна, даүаварились. Ну, так. Сасватали (В.А. Макаров, 1928 г. р., х. Дьяконовский); Да сватача прихадили, свадинки были... Тагда ужэ пажылые прихадили на свадинки, ево радня и наша радня вот, ани там биседавали, разгаваривали (А.В. Александрова, 1936 г. р., х. Калиновский).

Наиболее обширную группу языковых средств составляют единицы, характеризующие вступление в родственную связь посредством заключения брака (в том числе совершения обряда венчания). В исследуемом материале зафиксированы глаголы (по)жениться, (за)регистрироваться, расписываться, венчаться, глагольно-именные сочетания играть / гулять (свадьбу), а также неполный эквивалент сходиться: Вот када ууляли свадьбу, то уатовили чё, паштет уатовили (А.Я. Артеменко, 1931 г. р., с. Большая Ивановка); Нy, в этат день пажынились, расписываца - мы расписались... Цэркви не было́. Венчаца - не венчались (В.А. Макаров, 1928 г. р., х. Дьяконовский); Mbl вмести. Он мне дядя. Риүыстрирывались вмести... Заявление подали, пришли, расписались и ушли (П.П. Бароменская, 1931 г. р., с. Мачеха); Винчалси да армии... Супруга Валентина Стяпанавна... Мы ф пидисят дявятам уаду расписались (В.А. Обухов, 1941 г. р., ст-ца Тепикинская); Посли вайны, в шыстидесятам ани приехали, я с ним сашлась (А.Н. Додонова, 1926 г. р., ст-ца Тепикинская). Отмечено использование лексем, дифференцирующих вступление в брачный союз по гендерному признаку, - глаголов взаимосвязи жениться и контакта выходить (замуж): Я раньшы жыл на Типикинскай станицы. Там... Ну, патом здесь, жынился каүда (В.А. Макаров, 1928 г. р., х. Дьяконовский); А большы вот, каүда мамка выхадила замуш - з уалубями (А.Я. Артеменко, 1931 г. р., с. Большая Ивановка). Представлены также окказиональные сочетания уйти замуж, забрать замуж, отражающие покидание девушкой родного дома после замужества: А потом уже мать сама осталась, я замуж ушила (А.И. Зубкова, 1942 г. р., с. Семеновка); А потом матрю... туда забрали. Ну как замуж што ль (М.Д. Баранова, 1923 г. р., ст-ца Тепикинская).

Частотны в речи информантов и случаи использования глаголов приобретения и помещения с наречиями или терминами свойства при описании установления родственных отношений по линии «родители мужа / жены муж / жена»: взять сноху, взять зятем, попасть в зятья: Семья была, восьмую сноху взяли, своя семья - семь душ, да восьмую сноху привезли (А.В. Александрова, 1936 г. р., х. Калиновский); Он тоже сирота был. Ему притулииа негде было́, как раз тиф хадил, и памерли мать, и отеи, и бап$к а$, фсе папамерли, а он остался один. И сироту мы и взяли в зятья (О.М. Бочарова, 1901 г. р., х. Калачевский); Мама мая, Дуня её была звать, Евдакия Назаравна, ана значит за неё зятем взяли; А дочки вон, к адной в зятья папал, и вот нас народили (Е.Т. Ключкина, 1924 г. р., ст-ца Тепикинская).

Описывают диалектоносители и традиции выбора будущего супруга в дореволюционной России: $A$ мать - ани ши казачие, их сюда пириселяли. Мая прабабушка - ана чистакровная данская казачка. И тада же аддавали замуш: ребятам завязывали үлаза, девок в рят ставили - и хто каво паймаить, да. Иеё паймал Фёдор, он крипасной был. А ана - казачка, ани не были крепасными, каза́ки (А.В. Александрова, 1936 г. р., х. Калиновский). Отмечается и окказиональное употребление глагола передачи объекта отдавать, когда женщина подчеркивает значимость имущественных взаимоотношений при вступлении в брак: Замуж адда- 
вать нечим было́ (О.М. Бочарова, 1901 г. р., х. Калачевский).

Семантика 'установление духовного родства посредством обряда крещения' эксплицируется в речи глаголом крестить и донским диалектизмом кстить (СДГВО, вып. 3, c. 197). При этом диалектоносители могут недифференцированно использовать в речи обе лексемы, например: Да, я сваих кристил. [Тайно от советской власти?] $A$, не-е! Ни тайна. Кристить разришалась. Тада ни разришалась, шоб министрам, вроди, кстить... А так, пажалуста! Ну, кристили как: павизуть в иэркафь, а там, я ня знаю. Радителей ни пускали туда, а как, кум с кумой, каторых выюбрали, вот ани занясуть там в иэркву и фсё, уаварят - пирикрястили. А сам када кстился - я ни помню, малинький был (В.А. Макаров, 1928 г. р., х. Дьяконовский); А иэркоў была у Киквидзи. И уоот двенацать кило́метроў насили туды кстить дитей. Кристили (М.Т. Авилова, 1928 г. р., х. Дьяконовский).

Появление родственных отношений в силу объективных обстоятельств характеризует процесс усыновления / удочерения коголибо кем-либо после смерти одного / обоих родителей. В данном случае зафиксировано окказиональное употребление глагольно-именного сочетания взять сироту вместо узуального глагола усыновить: А он их обех пострелял. А сирота остался, шести месяиев мальчишка остался. И у нас уж тут мало стало у матери, она его взяла, и мы его и воспитывали (О.М. Бочарова, 1901 г. р., х. Калачевский).

Типовая семантика 'характер взаимоотношений кого-либо с кем-либо в рамках родственных связей' может быть конкретизирована частными значениями:

- 'иерархия семейных отношений';

- 'специфика эмоциональных отношений между членами семьи, родственниками'.

Указанные значения выражены в речи сельских жителей прежде всего посредством глаголов эмоционально-оценочного отношения, а также лексем некоторых других групп.
Благодаря воспоминаниям диалектоносителей можно получить представление о семейном укладе донских казаков и украинцев. Так, глаголы принуждения распоряжаться и речевого воздействия командовать указывают на существующую в семье иерархию отношений по линии «невестка - свекровь»: Патом бабушка рассказывала, как ани читыри снахи у печке адной и свикрофь, вот, свикрофь распоряжаеча, чё каму делать... У ниго была эта жана из другова сила. Ну, а када взяли, ана тожэ тут у печки, там свякруха, свякруха уссем камандывала тада (Д.В. Иванова, 1938 г. р., с. Большая Ивановка); языковые единицы с семантикой принуждения приказывать, управления не давать (самостоятельности) отражают систему отношений по линии «родители - дети»: Нуни знаю, какие слава. Ну приказывали, кагда молодым, приказывали: “Живите, живиme!» (3.М. Рогожина, 1928 г. р., с. Завязка); Ну в то время ещё такие абряды были, што атеи с матерью... самастаятельнасти не давали нам, маладёжи (М.М. Самоходкин, 1935 г. р., х. Дубровский).

В своих рассказах деревенские жители часто характеризуют эталон внутрисемейных отношений, акцентируя внимание на внутренних качествах человека как залоге мира и покоя в семье. Специфика отношений между членами семьи, родственниками выражается в лексиконе диалектоносителей в основном глаголами эмоционально-оценочного отношения, а также лексемами внешнего проявления отношения, эмоционального состояния, физического воздействия на объект, речевой деятельности, социальных отношений.

Чаще всего используются глаголы положительного эмоционально-оценочного отношения (любить, интересоваться). Они характеризуют взаимоотношения членов семьи по линии «бабушки / дедушки - внуки»: Ани кажут: "Як ие любить внучат - там чужа кровь». Ну я иэ можно их нэ любить, ани ш малэньки?! (В.Д. Магомедова, 1935 г. р., с. Мачеха); Я расла с бабушкай бальшынство: мама фсигда на работи, а я с свикровью с маминаю, с атиовай с матирью я вырасла, ана миня звала, фсё-фсё рассказывала, я интирисавалася фсем, чё ана менэ рассказываит (Д.В. Иванова, 1938 г. р., 


\section{РАЗВИТИЕ И ФУНКЦИОНИРОВАНИЕ РУССКОГО ЯЗЫКА}

с. Большая Ивановка). Отмечено также окказиональное использование глагола вращзаться, приобретающего в речи диалектоносителя значение речевого общения: Toш $x a x$ льь, но вот, та бабушка, но я с ней меньшэ в децтве вращалася, я большэ с этай (Д.В. Иванова, 1938 г. р., с. Большая Ивановка).

Связи по линии «родители - дети» обозначаются языковыми единицами с семантикой внешнего проявления отношения, приведения субъекта в эмоциональное состояние, речевого воздействия, подчинения: Ну благославляют с иконай кагда. Я благославляла сынавей (З.М. Рогожина, 1928 г. р., с. Завязка); Дитишечки у нас харошые. Ниплахие... Ни разу ничё миня ни абидели (П.П. Бароменская, 1931 г. р., с. Мачеха); Она всем угожала, всем зятьям (Е.В. Сидорова, 1939 г. р., с. Завязка). Разговорный глагол ладить «относиться к кому-либо дружески, быть с кемлибо в полном согласии, мире» (ТСРГ, с. 594) зафиксирован в сочетании с отрицательной частицей при характеристике сложных взаимоотношений двух поколений: Ни паладил он [муж] с атиом, канешна (А.Н. Додонова, 1926 г. р., ст-ца Тепикинская).

Отношения по линии «свекровь - невестка» репрезентируются в исследуемом материале глаголами эмоционального и функционального состояния бояться, (не) хотеть. Например, М.И. Корчакина из с. Семеновка, 1933 г. р., вспоминая свою свекровь, использует фразеологизм бояться как огня, подчеркивая интенсивность вызываемых чувств: $Н$ свекрофь мая була ох жестока, она була казачка. Я её баялась як аүня, пока она нэ умэрла; Р.П. Самоходкина из х. Дубровский, 1941 г. р., рассказывая о неприятии свекровью молодой невестки, использует сопоставительную конструкцию до того..., что и интонационно-выразительные средства: $H y$ в общем свякры миня ни хитела... Да таво ни хатела, што тако-о-й канфликт был, такое фс-ё-ё ни харошые...

Взаимоотношения мужа и жены часто эксплицируются единицами с семантикой отрицательного воздействия на объект (замучить, промучить): Ну ево [мужа]... Замучил. Да уже пятьдесят четыре года промучил (П.П. Бароменская, 1931 г. р., с. Мачеха); речевого общения (ругаться, ссо- риться, прост. лаяться): И мы разруяалися с мужыком, и яво атаслали на двачать или трицать киламетраф в лес (Н.И. Пономарева, 1929 г. р., с. Мачеха); Ну, если ссора яка-нибудь произойдэ или лаюиа, то обязательно она [мать] по-своему, а вин [отец] по-своему (В.Д. Магомедова, 1935 г. р., с. Мачеха); речевого воздействия (ругать): Муш миня тауда ругает (А.Е. Сафронова, 1941 г. р., ст-ца Тепикинская).

В рассказах о семье и родственном взаимодействии репрезентируется аксиологическая картина мира жителей края. В сфере межличностных отношений объектом ностальгии является утрата семейных ценностей, разрушение традиционных устоев. Чаще всего в зоне осмысления оказываются нормы поведения (прежде всего поведения женщин). Например, житель с. Завязка С.М. Лычагин, 1925 г. р., отмечает: Щас нарот какой-та друүой пашол... А када-та ж была фсеуда так: жэна баииа мужа, какой бы он ни был, а фсё ш таки муш, радной муш, он и пабьёт, он и примолвит. В данном высказывании норма поведения мужа описывается посредством контекстуальных антонимов глагола нанесения удара побить и диалектной лексемы с семантикой внешнего проявления отношения примолвить, то есть «приветливо, ласково отнестись к кому-либо, приветить, приласкать, принять под свою опеку» (СДГВО, вып. 4, с. 448). Образец отношения к мужу выражается с помощью глагола бояться, который одновременно характеризует состояние субъекта (страх) и указывает на зависимость этого состояния от объекта (муж), то есть обозначает негативное эмоционально-оценочное отношение.

4

Типовая семантика 'нарушение / утрата родственных связей' реализуется в частных значениях:

- 'утрата родственных связей, обусловленная какими-либо объективными обстоятельствами';

- 'нарушение / утрата родственных связей, обусловленные субъективными причинами'.

Первое из указанных значений выражается глаголами и глагольными конструкциями 
с семантикой отрицательного воздействия на объект (убить) и прекращения бытия (умереть, помереть, погибнуть, не припало пожить), например: У миня систра была в Лестюхах, стариая. А ее прицсидатель убил, абех пабил с мужем (О.М. Бочарова, 1901 г. р., х. Калачевский); Толька ни припала пажыть $c$ ним. Трициать лет ужэ без ниво я, помер (В.В. Черноусова, 1932 г. р., ст-ца Преображенская); Дядя у миня паүиб в армии вот в вайну, ну он и атеи паүиб (А.В. Парамонова, 1928 г. р., с. Завязка).

Утрата родственной взаимосвязи, вызванная какими-либо субъективными причинами, характеризует, как правило, отношения бывших супругов и обозначена глаголом расходиться: $\mathrm{Mbl} \mathrm{с} \mathrm{ним} \mathrm{быстра} \mathrm{разашлись} \mathrm{(А.Н.} \mathrm{До-}$ донова, 1926 г. р., ст-ца Тепикинская); Ну, уж я с мужьями фсё, ани уш папо́мерли, и мь разашлися, фсё, я с матрей жила (М.Д. Баранова, 1923 г. р., ст-ца Тепикинская).

Нарушение семейных отношений, обусловленное поведением субъекта в тех или иных обстоятельствах, выражается лексемами взаимоотношения, межличностных отношений, поступка и поведения. Так, нарушение брачных уз описывается с помощью просторечного глагола спутляться, то есть «вступить с кем-либо в какие-либо предосудительные отношения» (БАС, т. 14, с. 615): Hy вот, он кагда в армии был, Коршунаф эт Симён, а наш был жанатый. И с яво жыной. Ани братья дваюрадные. Ани с яво жаной он спутлялся (О.М. Бочарова, 1901 г. р., x. Калачевский); действия замужних женщин могут характеризоваться глаголами отношения и поведения нравиться, изменять, выкручиваться: Аказываца, жэна изменила, панравился другой, значит муш, и патом начинает выкручиваца (С.М. Лычагин, 1925 г. р., с. Завязка).

Народные обычаи могут способствовать появлению у слова оценочных коннотаций. Например, В.Д. Магомедова, 1935 г. р., так характеризует взаимоотношения родителей и поведение отца с другими женщинами: $H y$, жылы дружно, но вин [отец] страшно був ревнивый и страшно був ууляка - якый изэ казак, якый не үуляк. Чужых обязательно любыл, и сосидок, и фсих. Нарушение семейных отношений в данном высказывании обозначено глаголом положительного эмоционального отношения любить, указывающим на отношения мужа с другими женщинами. Интенсивность передаваемого признака подчеркивается наречием меры и степени обязательно и рядом однородных дополнений (чужих, соседок, всех). Слово гуляка в БАС толкуется как «человек, склонный к разгулу, к гульбе, кутила» (БАС, т. 3, с. 486), а в «Экспрессивном словаре диалектной личности»как «человек, ведущий разгульный, распутный образ жизни» и маркировано пометой «порицательное» (ЭС, с. 41). Однако выражение Якый ты казак, якый не гуляк позволяет понять, что рассматриваемое слово не содержит тех негативных коннотаций, которые свойственны данной лексеме в других говорах. Разгульное поведение донского казака не только не осуждалось, но и признавалось одной из неотъемлемых составляющих его образа жизни.

Отказ от родственных взаимоотношений зафиксирован при функционировании глагола интеллектуальной деятельности знать: Был председателем [брат]. Да он нас знать не знал (О.М. Бочарова, 1901 г. р., х. Калачевский).

\section{5}

Проведенное исследование глагольной лексики, эксплицирующей родственные отношения, позволяет выделить ядерные и периферийные конституенты поля. К ядру и приядерной зоне можно отнести глаголы взаимоотношения и межличностных отношений, которые выступают регулярным и специализированным средством выражения рассматриваемого значения, отличаются частотностью, разнообразием парадигматических, синтагматических и эпидигматических связей. К ближней периферии относятся глаголы речевой деятельности, бытия, эмоционального состояния, социальных отношений, к зоне дальней периферии - единицы иных семантических групп (движения, физического воздействия на объект, социальной деятельности, функционального состояния и некоторых других), выступающие неспециализированными и нерегулярными средствами выражения семантики 'родственные отношения' в структуре анализируемого лексикона. 


\section{СПИСОК ЛИТЕРАТУРЫ}

1. Балли, Ш. Язык и жизнь / Ш. Балли. - М. : Едиториал УРСС, 2003. - 232 с.

2. Баранникова, Л. И. Говоры территорий позднего заселения и проблема их классификации / Л. И. Баранникова // Вопросы языкознания. 1975. - № 2. - С. 22-31.

3. Касаткин, Л. Л. Донские казачьи говоры / Л. Л. Касаткин // Слово в тексте и в словаре : сб. ст. к семидесятилетию акад. Ю. Д. Апресяна / отв. ред. Л. Л. Иомдин, Л. П. Крысин. - М. : Языки русской культуры, 2000. - С. 582-590.

4. Кудряшова, Р. И. Слово народное. Говоры Волгоградской области в прошлом и настоящем / Р. И. Кудряшова. - Волгоград : Перемена, 1997. $124 \mathrm{c}$.

5. Лексикон диалектоносителей в языке региона на территориях смешанного проживания русских и украинцев / под общ. ред. проф. Н. А. Тупиковой. - Волгоград : Изд-во ВолГУ, 2014. - 200 с.

6. Речь носителей русского и украинского языков в пунктах смешанного проживания населения / Н. А. Тупикова, Д. Ю. Ильин, Н. А. Стародубцева ; под общ. ред. проф. Н. А. Тупиковой. - Волгоград : Изд-во ВолГУ, 2013. - 68 с.

7. Стародубцева, Н. А. Субстантивные средства выражения родства в лексиконе диалектоносителей (на материале речи жителей полиэтнических территорий Волгоградской области) / Н. А. Стародубцева // Вестник Волгоградского государственного университета. Серия 2, Языкознание. - 2015. № 4(28). -C. 16-24. - DOI: http://dx.doi.org/10.15688/ jvolsu2.2015.4.2.

8. Тупикова, Н. А. Выражение родственных взаимоотношений в воспоминаниях донских казаков / Н. А. Тупикова, Н. А. Стародубцева, И. А. Нелина // Лексический атлас русских народных говоров (Материалы и исследования) 2014. - СПб. : Нестор-История, 2014. - С. 626-634.

9. Тупикова, Н. А. Лексические параллели в речи представителей русско-украинских семей как отражение культурно-языковых контактов славянских народов / Н. А. Тупикова, Н. А. Стародубцева // Rosja w dialogu kultur. Tom 1. - Torun : Wydawnictwo naukowe Uniwersytetu Mikołaja Kopernika, 2015. - C. 303-317.

10. Тупикова, Н. А. Основные подходы к структурированию лексикона диалектоносителей в пунктах смешанного проживания населения / Н. А. Тупикова // Известия Южного федерального университета. Филологические науки. - 2013. № 4.- C. $36-42$.

11. Тупикова, Н. А. Функционально-семантические свойства глаголов состояния в речи диалектоносителей на территориях смешанного про- живания русских и украинцев / Н. А. Тупикова, О. В. Бондаренко // Вестник Волгоградского государственного университета. Серия 2, Языкознание. - 2016. - Т. 15, № 2. - C. 89-97. - DOI: http://dx. doi.org/10.15688/jvolsu2.2016.2.211.

\section{СЛОВАРИ}

$Б A C$ - Словарь современного русского литературного языка : в 17 т. / под ред. А. М. Бабкина, С. Г. Бархударова, Ф. П. Филина [и др.]. - М. ; Л. : Наука, 1950-1965.

СДГВО - Словарь донских говоров Волгоградской области / под ред. проф. Р. И. Кудряшовой. Вып. 1-6. - Волгоград : Изд-во ВГИПК РО, 20062009.

ТСРГ - Толковый словарь русских глаголов: Идеографическое описание. Английские эквиваленты. Синонимы. Антонимы / под ред. проф. Л. Г. Бабенко. - М. : АСТ-ПРЕСС, 1999. - 693 с.

ЭС-Нефедова, Е. А. Экспрессивный словарь диалектной личности / Е. А. Нефедова. - М. : Изд-во Моск. ун-та, 2001. - 144 с.

\section{REFERENCES}

1. Balli Sh. Yazyk i zhizn [Language and Life]. Moscow, Editorial URRS Publ., 2003. 232 p.

2. Barannikova L.I. Govory territoriy pozdnego zaseleniya i problema ikh klassifikatsii [Dialects of Late Settlement Areas and the Problem of Their Classification]. Voprosy yazykoznaniya, 1975. no. 2, pp. 22-31.

3. Kasatkin L.L. Donskie kazachyi govory [The Dialects of Don Cossacks]. Iomdin L.L., Krysin L.P., eds. Slovo $v$ tekste $i v$ slovare: sb. st. $k$ semidesyatiletiyu akad. Yu. D. Apresyana [The Word in the Text and in the Dictionary: Collection of Works Devoted to 70th Anniversary of Academician Yu.D. Apresyan]. Moscow, Yazyki russkoy kultury Publ., 2000, pp. 582-590.

4. Kudryashova R.I. Slovo narodnoe. Govory Volgogradskoy oblasti $v$ proshlom i nastoyashchem [The Popular Word. Dialects of the Volgograd Region in the Past and in the Present]. Volgograd, Peremena Publ., 1997. 124 p.

5. Tupikova N.A., ed. Leksikon dialektonositeley $v$ yazyke regiona na territoriyakh smeshannogo prozhivaniya russkikh i ukraintsev [Lexis of Dialects Speakers in the Language of Territories of Mixed Inhabitance of Russians and Ukrainians]. Volgograd, Izd-vo VolGU, 2014. $200 \mathrm{p}$.

6. Tupikova N.A., Ilyin D.Yu., Starodubtseva N.A. Rech nositeley russkogo i ukrainskogo yazykov 
$v$ punktakh smeshannogo prozhivaniya naseleniya [Native Russian and Ukrainian Speech in the Regions with Mixed Population]. Volgograd, Izd-vo VolGU, 2013. 68 p.

7. Starodubtseva N.A. Substantivnye sredstva vyrazheniya rodstva $\mathrm{v}$ leksikone dialektonositeley (na materiale rechi zhiteley polietnicheskikh territoriy Volgogradskoy oblasti) [Substantive linguistic Means Expressing Kinship in the Lexicon of Dialect Speakers (based on the speech of residents living in multi-ethic areas of the Volgograd region)]. Vestnik Volgogradskogo gosudarstvennogo universiteta. Seriya 2, Yazykoznanie [Science Journal of Volgograd State University. Linguistics]. 2015, vol. 14, no. 4, pp. 1624. DOI: http://dx.doi.org/10.15688/jvolsu2.2015.4.2.

8. Tupikova N.A, Starodubtseva N.A., Nelina I.A. Vyrazhenie rodstvennykh vzaimootnosheniy $\mathrm{v}$ vospominaniyakh donskikh kazakov [Expression of Kin Relationships in the Memories of the Don Cossacks]. Leksicheskiy atlas russkikh narodnykh govorov (Materialy i issledovaniya) 2014 [Lexical Atlas of Russian Folk Dialects (Materials and Research) 2014]. Saint Petersburg, Nestor-Istoriya Publ., 2014, pp. 626-634.

9. Tupikova N.A, Starodubtseva N.A. Leksicheskie paralleli $\mathrm{v}$ rechi predstaviteley russkoukrainskikh semey kak otrazhenie kulturnoyazykovykh kontaktov slavyanskikh narodov [Lexical Parallels in Speeches by Russian-Ukrainian Families as a Reflection of Cultural and Linguistic Contacts of the Slavic Peoples]. Rosja w dialogu kultur. T. 1 [Russia in the Dialogue of Cultures. Vol. 1]. Torun, Wydawnictwo naukowe Uniwersytetu Mikołaja Kopernika, 2015, pp. 303-317.

10. Tupikova N.A. Osnovnye podkhody $\mathrm{k}$ strukturirovaniyu leksikona dialektonositeley $\mathrm{v}$ punktakh smeshannogo prozhivaniya naseleniya [The Main Approaches to Structuring the Lexicon of Dialect
Speakers in the Regions of Settlements with Mixed Population]. Izvestiya Yuzhnogo federalnogo universiteta. Filologicheskie nauki, 2013, no. 4, pp. 34-42.

11. Tupikova N.A, Bondarenko O.V. Funktsionalnosemanticheskie svoystva glagolov sostoyaniya v rechi dialektonositeley na territoriyakh smeshannogo prozhivaniya russkikh i ukraintsev [The Functional and Semantic Properties of Stative Verbs in the Dialects of Mixed Russian and Ukrainian Settlements]. Vestnik Volgogradskogo gosudarstvennogo universiteta. Seriya 2, Yazykoznanie [Science Journal of Volgograd State University. Linguistics], 2016, vol. 15, no. 2, pp. 89-97. DOI: http://dx.doi.org/10.15688/jvolsu2.2016.2.11.

\section{DICTIONARIES}

Babkin A.M., Barkhudarov S.G., Filun F.P., eds. Slovar sovremennogo russkogo literaturnogo yazyka: $v 17 \mathrm{t}$. / pod red [Dictionary of Modern Russian Literary Language. In 17 vols]. Moscow; Leningrad, Nauka Publ., 1950-1965.

Kudryashova R.I., ed. Slovar donskikh govorov Volgogradskoy oblasti [Dictionary of Don dialects of Volgograd region]. Volgograd, VGIPK RO Publ., 20062009.

Babenko L.G., ed. Tolkovyy slovar russkikh glagolov: Ideograficheskoe opisanie. Angliyskie ekvivalenty. Sinonimy. Antonimy [Explanatory Dictionary of Russian Verbs: Ideographic Description. English Equivalents. Synonyms. Antonyms]. Moscow, AST-PRESS Publ., 1999. 693 p.

Nefedova E.A. Ekspressivnyy slovar dialektnoy lichnosti [Expressive Dictionary of Dialect Personality]. Moscow, Izd-vo Mosk. un-ta, 2001. 144 p.

\section{Information About the Author}

Natalya A. Starodubtseva, Candidate of Sciences (Philology), Associate Professor, Department of Russian Language and Documentation Studies, Volgograd State University, Prosp. Universitetsky, 100,400062 Volgograd, Russian Federation, natst1981@list.ru, iryas@volsu.ru.

\section{Информация об авторе}

Наталья Анатольевна Стародубцева, кандидат филологических наук, доцент кафедры русского языка и документалистики, Волгоградский государственный университет, просп. Университетский, 100, 400062 г. Волгоград, Российская Федерация, natst1981@list.ru, iryas@volsu.ru. 